\title{
Navigation Safety Evaluation of Xiamen port Based on AHP-Fuzzy
}

\author{
Pengfei Huang, Zhixiu Du*, Cuifang Cheng \\ College of Navigation, Jimei University, Xiamen,Fujian,China \\ e-mail: 13696952606@126.com
}

Keywords: Xiamen Port; navigation safety; Comprehensive evaluation; Countermeasures

\begin{abstract}
In order to safeguard the maritime navigation safety of Xiamen port and improve the efficiency of port operations, protect the marine environment, based on the analysis of various factors affecting the safety of Xiamen port navigation, we established navigation safety evaluation index system of Xiamen port, and then applied the Analytic Hierarchy Process AHP- Fuzzy comprehensive evaluation to evaluate the navigation safety of Xiamen port, and get the main factors affecting the navigation safety of Xiamen. According to the evaluation results, and combined with the characteristics and Present situation of Xiamen port, the paper proposed corresponding countermeasures and suggestions of various risks control.
\end{abstract}

\section{Introduction}

Xiamen port is one of the major coastal ports in China. It is an important hub of China's maritime transport, the hub of the southeast coast, and is the major shipping port for Taiwan[1]. There are many kinds of ship in Xiamen port, such as ship carrying dangerous goods and oil tanker, which contribute to busy traffic. Especially, since "three links" with Taiwan, increasing the vessel traffic flow, navigable waters environment becomes increasingly complex, sea traffic safety facing greater potential threat, has become the focus and content of the study in the future development of Xiamen port area[2].

However, most of the traffic risk assessment using traditional qualitative methods, such as the [3-6]in the literature only for traffic safety evaluation method, not for specific areas of security evaluation. The fuzzy comprehensive evaluation method in [7] was used to evaluate the risk of the port in Xiamen, but the results were not analyzed. BP Neural network in literature[8] was used to evaluate the traffic safety of urban roads and highways, but the results were not analyzed. In this paper, the AHP - fuzzy comprehensive evaluation method is used to evaluate the safety of navigation in Xiamen port, and to obtain the main factors that affect the safety of navigation in Xiamen port. According to the evaluation results, combined with the characteristics and present situation of Xiamen port, the countermeasures and suggestions are put forward to control all kinds of risks.

\section{The establishment of risk identification and evaluation index system of Xiamen port}

\subsection{Risk analysis of marine transportation in Xiamen port}

The research object of port navigation safety evaluation index system is the various factors affecting the safety of navigation. According to the traffic safety assessment content [9], the first level indicators are identified as human factors, ship factors, navigation environment factors and management factors, the factors are analyzed as follows:

(1)Human factors

The concept of "human" in the human factors contains not only the direct cause of marine accident crew, ship traffic management department related personnel, develop contingency plans for various technical and management personnel, but also contains pilotage operation involved in the 
pilot team, pilotage equipment, the pilot, pilotage environment pressure. In addition, improper operation of pilot will also cause maritime traffic accident. Therefore, human factors should be analyzed from professional level, team cooperation ability, operating environment, working environment, knowledge structure and the decision making ability.

(2)Ship factors

One of the important factors of maritime accidents is the ship. Therefore, the status of the condition of the ship should be evaluated. In addition, the ship itself is more complex, mainly composed of hull and a lot of equipment and instruments, etc. These factors play important role in analyzing maritime accidents.

(3)Navigation environment factors

Navigation environment factors that affect the safety of the ship could be summarized as the following:(1)ship collision and grounding because of busy traffic and poor natural environment, (2) ship collision, stranding and grounding because of wind, current, wave, fog and channel which lead to ship deviation or difficulties of ship handing behaviors, (3)due to the influence of the wind, wave, flow of the anchor, causing the ship collision, running aground or stranded[10].therefore, should consider the following aspects: hydrology and meteorology, the channel, anchorage, port terminals, traffic flow beacons and obstruction.

(4)Management factors

The main management content includes navigation environment, navigation order, as well as human activities related to management. The main management way includes regulations of ship traffic management, on-site cruise control, navigation mark management, water traffic management and organization, navigation security, etc. Ship traffic management involves lots of content, but ship management related to navigation has been included, mainly in the following several parts: contingency plans, pilotage, cruise factors, tugboat factors and VTS.

2.2 The establishment of marine traffic risk identification and evaluation index system of Xiamen port

According to the evaluation content of traffic safety in maritime traffic project, combining with the current situation of Xiamen port navigation safety, considering the characteristics of index value, referring to the port navigation safety evaluation index constructed in this article, and then extracting navigation safety evaluation index system of Xiamen port, detailed in the following table:

Table 1 Port navigation safety evaluation index system

\begin{tabular}{|c|c|c|c|}
\hline Target layer index A & First level index B & Second level index C & Third level index D \\
\hline \multirow{5}{*}{ 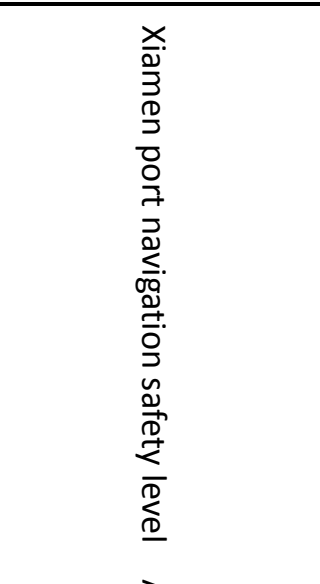 } & \multirow{6}{*}{ Human factors B1 } & $\begin{array}{l}\text { Professional level } \\
\text { C1 }\end{array}$ & \\
\hline & & $\begin{array}{l}\text { Team cooperation } \\
\text { ability } \mathrm{C} 2\end{array}$ & \\
\hline & & $\begin{array}{l}\text { Manipulator } \\
\text { condition C3 }\end{array}$ & \\
\hline & & $\begin{array}{l}\text { Working environment } \\
\text { C4 }\end{array}$ & \\
\hline & & $\begin{array}{l}\text { Knowledge structure } \\
\text { C5 }\end{array}$ & \\
\hline$\triangleright$ & & Decision making & \\
\hline
\end{tabular}




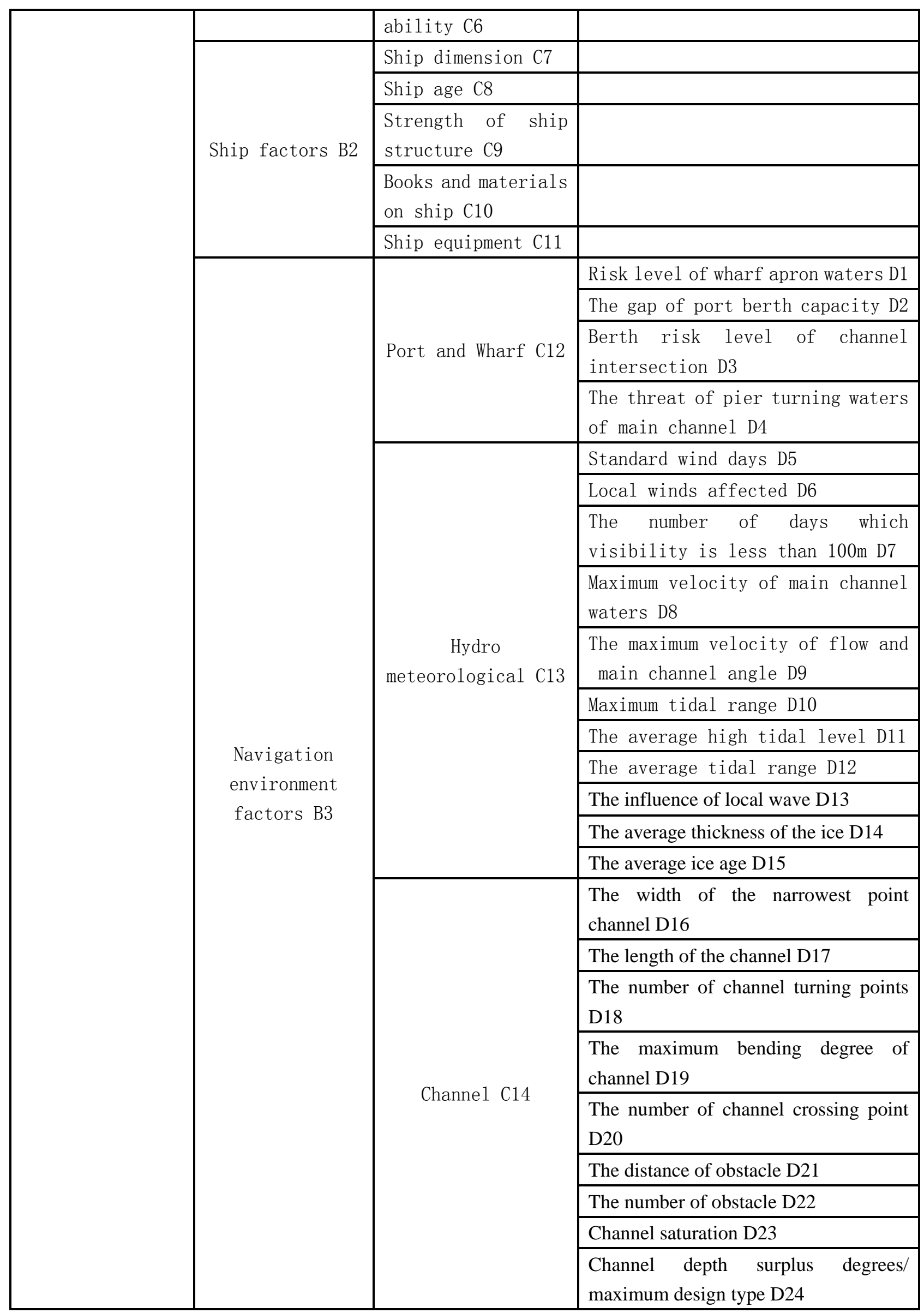




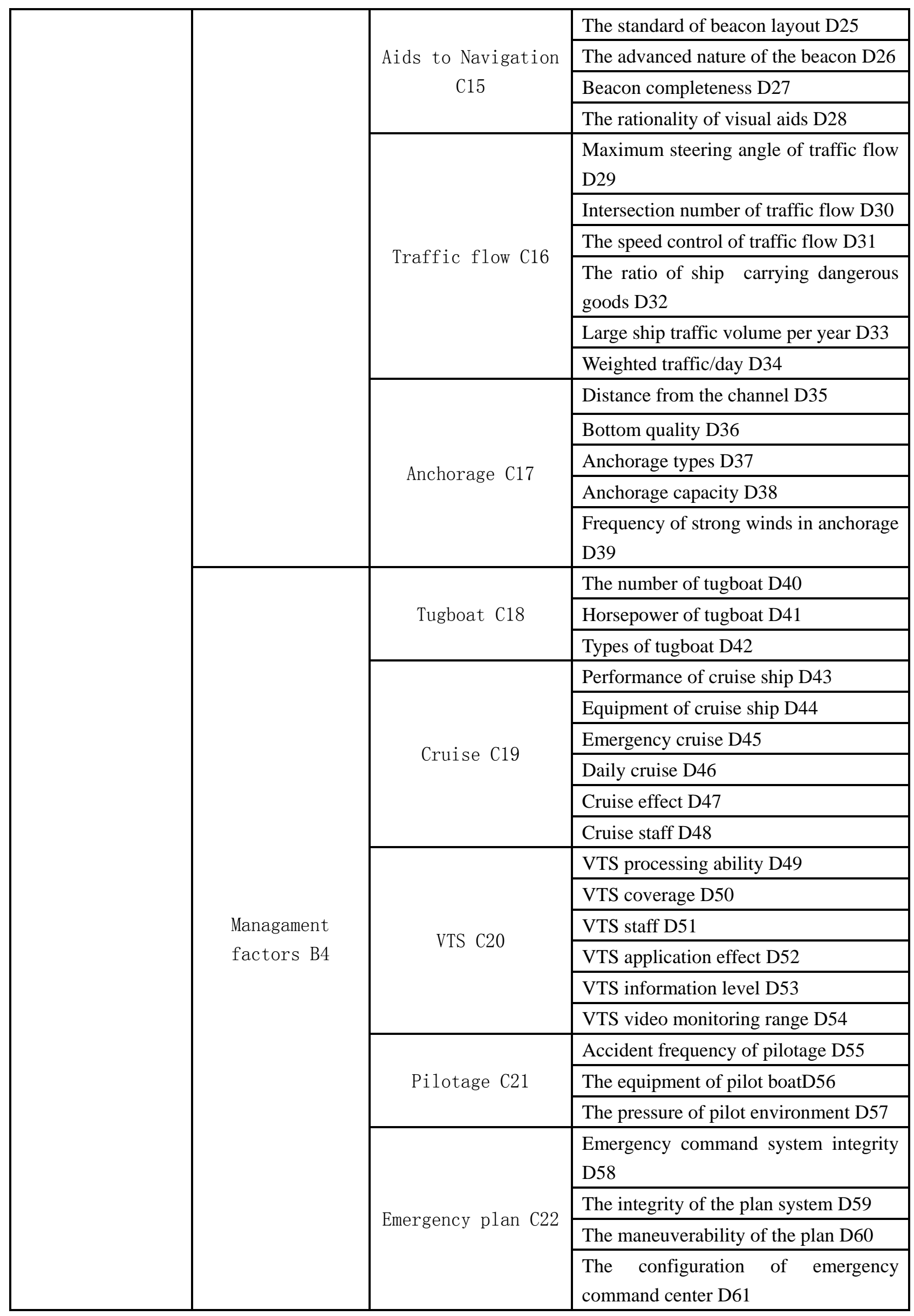




\begin{tabular}{|l|l|l|}
\hline \multirow{2}{*}{} & & $\begin{array}{l}\text { The level of emergency response } \\
\text { procedures D62 }\end{array}$ \\
\hline & $\begin{array}{l}\text { The social level of search and rescue } \\
\text { forces D63 }\end{array}$ \\
\hline & $\begin{array}{l}\text { The conditions of emergency funds } \\
\text { D64 }\end{array}$ \\
\hline & Emergency D65 \\
\hline
\end{tabular}

\section{The establishment of Xiamen maritime traffic safety evaluation model}

(1)set up factors set

In this paper, with $\mathrm{U}_{1}, \mathrm{U}_{2}, \mathrm{U}_{3}, \mathrm{U}_{4}$ on behalf of evaluation index of the human factor, ship factor, navigation environment factor and management factors. The factors set as follows:

$\mathrm{U}=\{$ human factor $\mathrm{U}$ 1, ship factor $\mathrm{U} 2$, navigation environment factor $\mathrm{U} 3$, management factor $\mathrm{U} 4\}$

(a)Human factorset

Human factor $\mathrm{U} 1=\{$ professional level $\mathrm{U} 11$, team cooperation ability $\mathrm{U} 12$, operator condition U13, working environment U14, knowledge structure U15, decision making ability U16 \}

(b)Ship factor set

Ship factor $\mathrm{U} 2=\{$ ship dimension U21, ship age U22, strength structure of ship U23, books and materials on the ship U24, ship equipment U25\}

(c)Navigation environment set

Navigation environment factor $\mathrm{U} 3=$ p port and pier U31,hydrometeorology U32, channel U33, beacon U34, traffic flow U35, anchorage U36 \}

(d)Management factorset

Environment factor U4 $=\{$ tugboat U41,cruise U42, (VTS ) U43, pilot U44, emergency plan U45

The rest hierarchy can be deducedfrom this.

(2)weight determination ${ }^{[11]}$

In this paper, we take the first layer of evaluation factors which including human factor, ship factor, navigation environment factor and management factor, as example to illustrate the calculation method of each index weight and the calculation process. According to the expert questionnaire, available judgment matrix is as follows:

$$
C=\left[\begin{array}{cccc}
1 & 3 & 2 & 2 \\
1 / 3 & 1 & 1 / 2 & 1 \\
1 / 2 & 2 & 1 & 2 \\
1 / 2 & 1 & 1 / 2 & 1
\end{array}\right] .
$$

(I)Column regulation

$$
\begin{aligned}
& \sum_{k=1}^{4} c_{k 1}=1+1 / 3+1 / 2+1 / 2=7 / 3 \\
& \bar{c}_{11}=0.4286 ; \bar{c}_{21}=0.1428 ; \bar{c}_{31}=\bar{c}_{41}=0.2143 ;
\end{aligned}
$$

By analogy :

New matrix will be available by above calculation : 


$$
C^{\prime}=\left[\begin{array}{cccc}
0.4286 & 0.4286 & 0.5 & 0.3333 \\
0.1428 & 0.1428 & 0.125 & 0.1667 \\
0.2143 & 0.2858 & 0.25 & 0.3333 \\
0.2143 & 0.1428 & 0.125 & 0.1667
\end{array}\right]
$$

(II)Add each line of $C^{\prime}$ :

$C_{1}=\sum_{j=1}^{4} \bar{c}_{1 j}=1.6905 C_{2}=\sum_{j=1}^{4} \bar{c}_{2 j}=0.5773 C_{3}=\sum_{j=1}^{4} \bar{c}_{3 j}=1.0834 \quad C_{4}=\sum_{j=1}^{4} \bar{c}_{4 j}=0.6488$. (III)Normalized vector $c=(1.6905,0.5773,1.0834,0.6488)^{T}$ :

$$
\sum_{i=1}^{4} C_{i}=1.6905+0.5773+1.0834+0.6488=4
$$

Calculate the corresponding weight:

$$
W_{1}=\frac{C_{1}}{\sum_{i=1}^{4} C_{i}}=0.4226
$$

$W_{2}=0.1443 ; W_{3}=0.2709 ; w_{4}=0.1622$.

(IV)Calculate the maximum characteristic root of the judgment matrix $\mathrm{C}$ :

$$
\begin{aligned}
& C_{W}=\left[\begin{array}{cccc}
1 & 3 & 2 & 2 \\
1 / 3 & 1 & 1 / 2 & 1 \\
1 / 2 & 2 & 1 & 2 \\
1 / 2 & 1 & 1 / 2 & 1
\end{array}\right]\left[\begin{array}{l}
0.4226 \\
0.1443 \\
0.2709 \\
0.1622
\end{array}\right]=\left[\begin{array}{l}
1.7217 \\
0.5828 \\
1.0952 \\
0.6533
\end{array}\right] . \\
& \lambda_{\max }=\sum_{i=1}^{4} \frac{\left(C_{W}\right)_{i}}{n W_{i}}=4.0458 .
\end{aligned}
$$

(V)Test the consistency of the matrix

$$
C I=\frac{\lambda_{\max }-n}{n-1}=\frac{4.0458-4}{4-1}=0.015267,
$$

lookup table available, when the dimension $n=4$, and RI=0.8980, therefore $C R$ :

$$
C R=\frac{C I}{R I}=\frac{0.015267}{0.8980}=0.017<0.10 .
$$

CR has the satisfactory consistency.

Therefore, the judgement matrix of human factor, ship factor, navigation environment factor and 
management factor has consistency, and the weight of these four factors are shown in table below:

Table 2 index weight of $U_{1}$ layer

\begin{tabular}{|c|c|c|c|c|}
\hline $\mathrm{U}$ & Human factor $\mathrm{U}_{1}$ & Ship factorU & $\begin{array}{c}\text { navigation } \\
\text { environment factorU }\end{array}$ & $\begin{array}{c}\text { Management } \\
\text { factor } \mathrm{U}_{4}\end{array}$ \\
\hline Weight value & 0.4226 & 0.1443 & 0.2709 & 0.1622 \\
\hline
\end{tabular}

In the same way, factors weight of Xiamen navigation safety evaluation index system can be calculated.

\section{Xiamen maritime traffic safety comprehensive evaluation}

(1)To build judgmentset

The judgment set is also called evaluation set, which is a collection of the evaluation results of the evaluation object. The judgment set rules the choice scope of all the evaluation factors in the evaluation results. The results can be qualitative, also can be quantified by the score ${ }^{[11]}$. According to the relevant national standards and the actual situation of Xiamen port, the evaluation level is defined as 5 levels, the index evaluation set and evaluation criteria of target level (top level) are as follows:

$$
V=\left\{V_{1}, V_{2}, V_{3}, V_{4}, V_{5}\right\}=\{\text { low, lower, general, high, dangerous }\}=\{0-1,1-2,2-3,
$$

$$
3-4,4-5\} \text {. }
$$

The membership degree is the basis of solving practical problems by using fuzzy comprehensive evaluation theory. The correct membership function is the key to describe fuzzy control ${ }^{[11]}$. The evaluation criteria for each risk level of the lowest level indicators were determined by statistical analysis method, the relevant research results, relevant technical standards, expert consultation and questionnaire survey. Evaluation level of assignment by adopting the combination of quantitative and qualitative methods, including: historical data, industry standard, the method of literature, expert evaluation method and other theories. With "the distance between anchorage and channel" comment sets an example, explaining the process of the establishment of the quantitative indicators of membership degree, as following table 3:

Table 3 evaluation standard of distance between anchorage and channel

\begin{tabular}{|c|c|c|c|c|c|}
\hline \multirow{2}{*}{$\begin{array}{c}\text { Evaluation } \\
\text { standard }\end{array}$} & \multicolumn{5}{|c|}{ level } \\
\cline { 2 - 6 } distance & Lower risk & Low risk & general & dangerous & High dangerous \\
\hline$\geq 5$ & $3 \sim 5$ & $1.5 \sim 3$ & $1 \sim 1.5$ & $\leq 1$ \\
\hline
\end{tabular}

Note: according to the plane design specification requirements of seaport in China, the safe distance between edge of harbor anchorage and sideline of channel should meet the following requirements: outside the port of anchorage should not be less than 2 to 3 times of the length of the design ship; when using single anchor or single buoy mooring, port anchorage should not be less than the length of the design ship; adopting double buoy mooring should not be less than 2 times of the width of design ship. Therefore.

By above knowledge, $\mathrm{v}_{1}=5, \mathrm{v}_{2}=3 \sim 5, \mathrm{v}_{3}=1.5 \sim 3, \mathrm{v}_{4}=1 \sim 1.5, \mathrm{v}_{5}=1$, and the average 
distance between anchorage and channel (the times of length of design ship) $x_{1}=2$. Detailed calculation as followings:

Because $\mathrm{v}_{3}>\mathrm{x}_{1}>\mathrm{v}_{4}$, therefore $r_{3}=\frac{3-2}{3-1.5}=0.667, r_{4}=1-r_{3}=0.333, r_{1}=r_{2}=r_{5}=0$.

As a result, the evaluation sets of distance between anchorage and channel is $[0,0,0.667,0.333$, 0]. It means $66.7 \%$ risk of distance between anchorage and channel of navigation safety of Xiamen port belongs to "general", while $33.3 \%$ belongs to "dangerous". According to above steps to calculate indicators of membership grade and to gather all of membership grade, then to get comprehensive evaluation matrix. Take environment factor of navigation as an example, as following table 4:

Table 4 Comprehensive evaluation matrix of environment factor of navigation

\begin{tabular}{|c|c|c|c|c|c|c|c|c|}
\hline \multirow{2}{*}{$\begin{array}{l}\text { Target } \\
\text { layer A }\end{array}$} & \multirow{2}{*}{$\begin{array}{c}\text { First } \\
\text { level B }\end{array}$} & \multirow{2}{*}{$\begin{array}{l}\text { Second } \\
\text { level C }\end{array}$} & \multirow[b]{2}{*}{ Third level D } & \multicolumn{5}{|c|}{ Fuzzy comprehensive evaluation matrix } \\
\hline & & & & lower & low & general & dangerous & $\begin{array}{c}\text { High } \\
\text { dangerous }\end{array}$ \\
\hline \multirow{5}{*}{$\begin{array}{l}\text { Naviga } \\
\text { tion } \\
\text { safety } \\
\text { level of } \\
\text { Xiame } \\
\text { n port }\end{array}$} & \multirow{5}{*}{$\begin{array}{c}\text { Navigat } \\
\text { ion } \\
\text { factor } \\
(0.2845 \\
)\end{array}$} & \multirow{5}{*}{$\begin{array}{c}\text { Anchora } \\
\text { ge } \\
(0.0929)\end{array}$} & $\begin{array}{c}\text { Distance from } \\
\text { channel } 0.2506\end{array}$ & 0.00 & 0.00 & 0.667 & 0.333 & 0.00 \\
\hline & & & $\begin{array}{c}\text { Bottom type of } \\
\text { anchorage } 0.1614\end{array}$ & 0.2 & 0.35 & 0.25 & 0.15 & 0.05 \\
\hline & & & $\begin{array}{c}\text { Type of anchorage } \\
0.1164\end{array}$ & 0.2 & 0.25 & 0.35 & 0.15 & 0.05 \\
\hline & & & $\begin{array}{c}\text { Anchorage } \\
\text { capability } 0.3227\end{array}$ & 0.1 & 0.3 & 0.4 & 0.15 & 0.05 \\
\hline & & & $\begin{array}{c}\text { Frequency of } \\
\text { strength wind } 0.1489\end{array}$ & 0.2 & 0.35 & 0.25 & 0.15 & 0.05 \\
\hline
\end{tabular}

(1) Calculation of comprehensive evaluation

According to formula

$$
B_{i}=W_{i}^{*} R_{i}
$$

Note: $\boldsymbol{B}_{\boldsymbol{i}}$ is comprehensive fuzzy calculation, which combines the indicator of penultimate layer;

$W_{i}$ is the weight matrix, $R_{i}$ is the matrix of fuzzy comprehensive evaluation, which means the relationship of evaluation set of the indicator of penultimate layer.

It is able to work out the comprehensive evaluation matrix of upper level by calculating all of the indicators of bottom level. By analogy, the matrix of fuzzy comprehensive evaluation of target level can be figured out.

Matrix of fuzzy comprehensive evaluation of navigation safety level of Xiamen port, as following table.

Table 5 Matrix of fuzzy comprehensive evaluation of navigation safety level of Xiamen port

Navigation Fuzzy comprehensive evaluation matrix 


\begin{tabular}{|c|c|c|c|c|c|}
\hline safety level of & lower & low & general & dangerous & High dangerous \\
\cline { 2 - 6 } Xiamen port & $0-1$ & $1-2$ & $2-3$ & $3-4$ & $4-5$ \\
\cline { 2 - 6 } & 0.1771 & 0.3250 & 0.2786 & 0.1808 & 0.0385 \\
\hline
\end{tabular}

(2)Make results of fuzzy comprehensive evaluation clearer

The method of Centroid de-fuzziness make the results of evaluation much clearer :

The results of fuzzy comprehensive evaluation

$=0.1771 * 0.5+0.3250 * 1.5+0.2786 * 2.5+0.1808 * 3.5+0.0385 * 4.5=2.0786$

According to evaluation set $V=\{$ lower,low,general,danger,high danger $\}=\{0-1,1-2,2-3,3-4,4-5\}$;

$2.0786 \in[2-3]$, it able to get the result of navigation safety level of Xiamen port is "general".

\section{Measurements and suggestions to improve the safety level of maritime transportation of}

\section{Xiamen port}

In order to improve the safety level of maritime transportation of Xiamen port, it should take corresponding measurements to reduce risk. some countermeasures and suggestions are available as following:

(1) With the rapid development of economy of Xiamen port, more and more large ship will be in and out of Xiamen port. Large ships need to take advantage of the tide to be into harbor and the existing channel is for one-way, which resulting in impossible for encounter and avoidance between ships in the channel, and thus brings difficulties to the supervision of ships in Xiamen port. Therefore, the supervision of large ships will be focus of the present and future regulation.

(2) Due to terrain of Xiamen bay and close range between anchorage and channel, there is traffic risk. Therefore, it needto strengthen the supervision of mooring ship, to prevent the anchor into the channel.

(3) From the evaluation results, the performance and the characteristics of the cruise ship in Xiamen harbor can not fully meet the needs of port development. So,it suggests that improving the performance of cruise ship, increasing the related proposals, enhancing the purpose, planning, coverage and effectiveness of cruise work, strengthening the key segment, key part, key water area and dynamic law enforcement of key ship, as well as maintaining the order of navigation.

(4) The traffic flow of Xiamen port is complex, with lots of intersections between ships. Some ships do not comply with the relevant provisions of maritime navigation, improper operation of some crews and pilot factors, which are the main causes of contact damage accident. Therefore, it should strengthen the supervision of large ships and increase the supervision of facilities and equipment.

\section{Conclusion}

The research on the maritime traffic safety of port is the foundation to promote the rapid and efficient development of port.This paper uses the mathematical method to evaluate the safety of port navigation, and combines the characteristics and the present situation of Xiamen port, then to put forward corresponding measurements and suggestions to control various kinds of risks.Hopefully, these measurements and suggestions may provide maritime transportation safety of Xiamen port with reference. 


\section{Reference}

[1]Writing Group of Xiamen Medium and Long Term Science and Technology Development Plan Outline.Xiamen Medium and Long Term Science and Technology Development Plan Outline(2006-2020)[Z].2006

[2]WANG Er-fang, LI Xiang-xian, CHEN Zong-bin. Grid risk assessment and management of traffic safety in the west of Xiamen port[J].Word Shipping,2015.01(38):37-40.

[3]LA Ba.Traffic safety assessment based on road alignment[J].Jiangxi Building Materials,2015(01):186-189.

[4]ZENG Jun-wei,ZHANGJin-long,QIAN Yong-sheng. A study on evaluation methods of road traffic safety[J].Logistics Technology,2014(12):1-2.

[5]ZHENG Jin-gang.Highway Traffic safety evaluation method and system[J]. Transportation Standardization,2014.5(9):153-157.

[6] LI Zhi-zhong,WANG Xiao-an,HE Lei,etc..Highway evalution based on subjective and objective security[J].Highway,2013(11):127-132.

[7] HUANG Xian-xin,SHAOZhe-ping,WANG Ping,etc..Risk factor evaluation on the navigational channels of Xiamen Port based on fuzzy comprehensive evaluation[J]. Journal of JimeiUniversity(Natural Science),2013.5(3):192-197.

[8]CHEN Jun,LICongying,DINGGuangming. Traffic safety assessment of freeway based on BP neural network[J]. Journal of TongjiUniversity(Natural Science), 2008.7(7):927-931.

[9]WU Zhao-lin,ZHU Jun. Marine traffic engineering[M].Dalian: Dalian Maritime University Press, 2004.

[10]DUAN Ai-yuan.Application of formal safety assessment (FSA) to the shipping traffic safety management of the port and its adjoining waters[D]Hubei:Huazhong University of Science and Technology,2006.

[11]DU Zhi-xiu.Research on route planning assessment model based on ECS[D].Xiamen: Jimei University,2012. 